\title{
"Ter ou não ter? eis a questão!" Crenças de alunos de secretariado executivo sobre o sotaque do falante nativo de inglês
}

\author{
"To have or not to have? that is the question!" \\ executive secretarial students' beliefs about the English \\ native speaker accent
}

\section{Fernando Silvério de Lima ${ }^{1}$}

\begin{abstract}
RESUMO: O presente trabalho analisa as crenças de vinte e um alunos de secretariado executivo sobre o sotaque do falante nativo em uma disciplina de língua inglesa de uma universidade federal localizada em Minas Gerais. As crenças foram levantas a partir de questionários e o mapeamento delas se deu a partir da análise de conteúdo, uma vez que foram categorizadas tematicamente, revelando traços marcantes sobre como os universitários concebem o papel da pronúncia e o sotaque do falante nativo de inglês em sua aprendizagem da nova língua. Os resultados mostram que a pronúncia é vista como um aspecto muito importante para a maioria deles, no entanto, quando comparada com as demais atividades fica em segundo plano, pois para os alunos a oralidade e a compreensão auditiva são os aspectos que eles esperam desenvolver naquela disciplina. O sotaque do falante nativo é considerado como parâmetro da pronúncia correta, o que justifica a maioria do grupo idealizá-lo como objetivo. Os alunos justificam essa crença afirmando que isto será bastante útil para obtenção de empregos e sucesso profissional. O estudo aponta para a necessidade de que alunos e professores reflitam sobre as consequências de suas crenças e que a disciplina de língua inglesa pode ser espaço para essas discussões.
\end{abstract}

PALAVRAS-CHAVE: Crenças. Sotaques. Falante Nativo de inglês. Falante Estrangeiro. Universitários.

ABSTRACT: This paper discusses the beliefs of twenty-one executive secretarial undergraduates about the native speaker accent in an English course at a federal university located in Minas Gerais, Brazil. The beliefs were mapped out through questionnaires and were portrayed through content analysis. The beliefs were thematically categorized, revealing important traits of how the undergraduates perceive the role of pronunciation and the native speaker accent while learning a new language. The results show that pronunciation is perceived as a very important issue for them, however, when compared to other types of classroom activities it ranks in a different

\footnotetext{
${ }^{1}$ Doutorado em Estudos Linguísticos pela Universidade Estadual Paulista de São José do Rio Preto (UNESP/IBILCE). Contato: limafs/@hotmail.com
} 
position, with a clear preference towards conversation and listening as skills they can develop in the course. The native speaker accent is considered the parameter for sounding correctly, explaining why most of the group idealizes it as purpose. The students explain their beliefs by saying that sounding like a native will be useful to get better jobs and achieve professional success. The study points out that students and teachers need to think about the consequences of their beliefs and that the English language course can be the space for such discussions.

KEYWORDS: Beliefs. Accents. English Native Speaker. Foreign Speaker. Undergraduates.

\section{Introdução}

Muitos aprendizes ao iniciarem um curso de inglês têm a proficiência linguística como principal objetivo a ser alcançado e se possível, o quanto antes. Outros ainda vão além, desejando não apenas a capacidade de se comunicar na nova língua, mas de interagir da mesma forma que os falantes de inglês como primeira língua (L1), ou seja, de adquirir o sotaque deles. Na Linguística Aplicada (LA) já existem trabalhos que problematizam a respeito de crenças de estudantes brasileiros sobre sotaque, no entanto, nos principais casos, os alunos são graduandos de Letras em estudos da linha de pesquisa de formação de professores de línguas. Neste artigo, optamos também pelo estudo de crenças de alunos universitários, que se diferenciam por não serem futuros professores de inglês, mas porque também necessitarão dessa língua na futura profissão.

Consideramos alguns estudos já realizados dentro da Linguística Aplicada na área de crenças no ensino de línguas e mais especificamente de crenças sobre sotaque (BARCELOS, 2003; CRUZ, 2007; SANTOS, 2010). Somamos a isso algumas questões sobre o papel da língua inglesa no mundo contemporâneo marcado pela globalização (GRADDOL, 1997, 2006; HALL, 2011; HARMER, 2001; KUMARAVADIVELU, 2012) e suas implicações para o ensino de línguas (CANAGARAJAH; WURR, 2011; JENKINS, 2000, 2007; PENNYCOOK, 1994; SCHMITZ, 2012, 2016). Tais perspectivas permitem compreender as crenças dos 
alunos de secretariado sobre pronúncia e o sotaque do falante nativo ${ }^{2}$ e discutir como elas podem influenciar a aprendizagem desses sujeitos, ao tomá-las como forma de fazer sentido da realidade e dos fenômenos que vivenciam.

Para iniciar a discussão, apresentamos a seguir as bases teóricas aqui brevemente mencionadas. Posteriormente, apresentamos um perfil dos participantes do estudo e os instrumentos metodológicos para coleta e análise dos dados. Em seguida, mapeamos e analisamos as crenças dos alunos de secretariado sobre sotaques e a aprendizagem de inglês. E por fim, retomamos os resultados pensando em suas implicações para o cenário atual, sugerindo também investigações futuras para que mais estudos de crenças discentes (não apenas de graduandos de Letras) venham a ser realizados na LA.

\section{O inglês no mundo globalizado e a necessidade da comunicação}

Desde o final do século XX, a língua inglesa (LI) deixou de ser vista apenas como uma opção adquirindo um status de necessidade (GRADDOL, 2006; PENNYCOOK, 1994; SCHMITZ, 2016). Na universidade, tanto na graduação quanto na pós-graduação, os alunos sentem cada vez mais essa necessidade nos artigos que devem ser lidos ou nas oportunidades de intercâmbio, bolsas de estudo e estágios que exigem cada vez mais a proficiência na língua inglesa dos candidatos. Neste cenário do inglês global, é cada vez maior o número de falantes de inglês como língua estrangeira (GRADDOL, 1997; HALL, 2011; HARMER 2001; KUMARAVADIVELU, 2012; SCHMITZ, 2012, 2016) e para acompanhar as novas gerações de falantes de inglês, os países buscam investir, de diferentes formas e com diferentes prioridades, na formação de seus professores e no processo educativo como um todo.

Mesmo com essa grande expansão numérica de falantes de LI como língua estrangeira (LE), sempre se fortaleceu uma crença no falante nativo (FN) como

\footnotetext{
${ }^{2}$ Consideramos especificamente o sotaque do falante nativo (SFN) de língua inglesa ao longo deste trabalho. Pertencem a este grupo os falantes que aprenderem esse idioma como primeira língua (JENKINS, 2007; SCHMITZ, 2012).
} 
padrão linguístico, ou como diz Graddol (2006, p.114), como "o padrão de ouro; os árbitros finais de qualidade e autoridade" (grifos nossos). Mesmo que já existam atitudes diferentes desta, a valorização desse padrão de ouro é frequentemente mencionada em estudos com graduandos de Letras (BARCELOS, 1995; CRUZ, 2007), conforme será discutido adiante, e que será comparado posteriormente com nossos resultados. Valida-se, portanto, uma crença: se temos que aprender outra língua, tomaremos os falantes nativos dessa língua como ponto de referência. Ao passo que esta pode ser uma motivação para os aprendizes se esforçarem, ela também merece ser ponderada, uma vez que, para assimilar um novo sotaque o falante está abrindo mão de traços particulares de sua história como aprendiz, de seu contexto cultural e de seu jeito natural de produzir os sons de sua fala.

Em contrapartida, perspectivas críticas dentro da Linguística Aplicada (LA) têm defendido a ressignificação ou desconstrução das visões clássicas de ensinoaprendizagem que tomam o falante nativo como referência (SCHMITZ, 2012, 2016). Com seu status de língua hegemônica (PENNYCOOK, 1994), que no cenário internacional é propagado junto ao discurso de oportunidades e participação no mundo globalizado, encontramos a forte influência do protagonismo do falante nativo tanto nos materiais pedagógicos exportados, quanto nas próprias metodologias de ensino geralmente originadas nos países que têm 0 inglês como L1 (considere os métodos audiolingual e ensino comunicativo como alguns exemplos).

Nos estudos do ensino de inglês como língua franca (ILF) ${ }^{3}$, as críticas mais pontuais ressaltam que questões como sotaque e pronúncia precisam de uma reorientação, ou como explica Schmitz (2012), um divórcio entre o ensino de línguas e o falante nativo como padrão a ser reproduzido. Mas, além disso, são necessários encaminhamentos pedagógicos específicos aos aprendizes de inglês

\footnotetext{
${ }^{3}$ Tradução para o termo English as a Lingua Franca (ELF) que considera o uso de uma língua em comum para interações entre falantes em contextos multiculturais cujas línguas maternas são diferentes.
} 
da comunidade internacional, como já se vê em trabalhos sobre fonologia para o inglês como língua internacional (JENKINS, 2000). Tais encaminhamentos pedagógicos são embasados por dois princípios basilares: o da inteligibilidade (a comunicação com foco na compreensão, sem exigência de assimilação de sotaques) e a liberdade de expressar-se (garantias de que ideias e identidades são respeitadas nas interações).

Enquanto isso, os esforços dos países do globo para promover o domínio da língua internacional surgem das mais diversas formas. Ao ponderar sobre alguns esforços redobrados de países como o Brasil, acerca do ensino de língua inglesa frente a um panorama de defasagem, Graddol (2006, p.28) sugere que a importância desta língua se intensifica, pois ela vai ao encontro das necessidades da "realidade global emergente". A globalização 4 é apresentada como principal agente responsável pelas transformações da realidade, tendo em vista que ela afetou o mundo pelo menos de três maneiras: na diminuição de espaço, tempo e fronteiras (CANAGARAJAH; WURR, 2011; GRADDOL, 1997, 2006; SCHMITZ, 2012, 2016). A necessidade de aproximação entre as nações como parte das interações globais (na economia, nas telecomunicações, dentre outros exemplos) favoreceu a língua inglesa como sua mediadora oficial e os falantes nativos desse idioma passaram a ser vistos como o ponto de referência não apenas para aprendizes, mas para editoras de livros e o desenvolvimento de metodologias de ensino.

Assim, mesmo no mundo globalizado em que a quantidade de falantes de inglês como LE supera a de falantes nativos (GRADDOL, 2006; SCHMITZ, 2016), torna-se relevante considerar quais crenças estes falantes têm em relação ao sotaque nativo e quais os possíveis impactos delas nas experiências de (tentar) aprender essa língua internacional. Dessa forma, retomamos os conceitos de crenças e sotaque que orientam nossa análise apresentada posteriormente.

\footnotetext{
${ }^{4} \mathrm{~A}$ integração de diferentes economias e o comércio intensificou o investimento em diferentes nações gerando desde movimentos migratórios até a produção de novo conhecimento. Do ponto de vista crítico, a globalização trouxe também efeitos graves como o aumento da poluição, as mudanças climáticas, o aumento do consumismo e a desigualdade social.
} 
"Ter ou não ter? eis a questão!" Crenças de alunos de secretariado executivo sobre o sotaque do falante nativo de inglês

\section{As Crenças e os Sotaques no Ensino de línguas}

Pesquisar as crenças de diferentes povos e sociedades já é uma tradição de longa data em diferentes áreas como a Antropologia e as Ciências Sociais ${ }^{5}$. Em áreas como a Educação e a Linguística Aplicada, o estudo desses fenômenos favoreceu a compreensão da maneira como os sujeitos interpretam práticas culturais diversas como os processos de aprender e ensinar. Ao analisar cronologicamente a expansão deste conceito no campo da LA, Barcelos (2007) explica que a pesquisa de crenças sobre aprender e ensinar línguas emergiu nos Estados Unidos na década de 1980 e encontrou seus primeiros caminhos no Brasil durante os anos 1990 com grande expansão nas décadas posteriores até os dias atuais.

As crenças compreendem as construções da realidade (BARCELOS, 2003, p.18) das pessoas ou, de uma vertente histórico-cultural atuam como mediadoras da experiência e sinalizadoras das mudanças da vida das pessoas. Tal conceito implica na percepção do sujeito sobre o mundo que o cerca, as pessoas com quem ele interage, as ações que realiza e os sentidos que permeiam todas essas experiências. As relações humanas em geral são mediadas por linguagem que é entendida como uma ferramenta que desenvolve as capacidades cognitivas e cria novas condições de desenvolvimento histórico-cultural das sociedades (VYGOTSKY; LURIA, 1993) ${ }^{6}$. É pela linguagem (a comunicação, a fala), que se

\footnotetext{
${ }^{5}$ Do ponto de vista linguístico, existem diferentes possibilidades dos estudos de crenças. Há quem as estude a partir da Psicologia, inserindo também o conceito de atitudes em suas teorizações, como se vê em análises influenciadas pelos trabalhos de William Labov na Sociolinguística e de William Lambert e Wallace Lambert na Psicologia Social. Neste trabalho, partimos da tradição originada nos estudos de ensino-aprendizagem da LA e propomos o diálogo com a teoria histórico-cultural. Desta forma, tratamos crenças como um conceito completo ao invés de desdobrá-los em outros conceitos como atitudes. Como discutiremos aqui, a perspectiva históricocultural possibilita interpretar crenças como significados da vida social (interpessoal) construídos pelas pessoas (intrapessoal), ou seja, representações psicológicas que retratam eventos e experiências nesse movimento do social ao individual.

${ }^{6}$ Alguns trabalhos em Linguística Aplicada propõem um diálogo a partir da Psicologia históricocultural de Vygotsky, Luria e Leontiev para o estudo de crenças. Para isso é necessário compreender essa proposta teórica a partir de sua historicidade. Vygotsky e seus colaboradores buscavam construir, na extinta União Soviética, uma Psicologia capaz de dar conta dos principais problemas de uma sociedade que atravessava um novo projeto político: a construção de uma
} 
constitui de enunciados e unidades de significação, e pelas ações concretas que as pessoas ensinam todo o conhecimento produzido como parte específica daquela cultura.

As crenças representam a generalização da experiência que 0 indivíduo faz de uma cultura da qual ele começa a fazer parte quando nasce (ou antes mesmo de nascer, se considerarmos as expectativas que os outros projetam sobre a criança, como no caso de seus familiares). Ao longo da história de seu desenvolvimento, o sujeito internaliza as práticas sociais de seu contexto e constrói sentido sobre si, sobre os outros e sobre o mundo. Cabe ressaltar que, sentido na perspectiva histórico-cultural é entendido como o conjunto de eventos psicológicos (VYGOTSKY, 2012) que surgem na atividade cognitiva das pessoas e são mediados por linguagem (a fala, as palavras, os conceitos). Estudar crenças, nessa perspectiva é buscar entender o papel mediador nesse sentido que os sujeitos constroem pela linguagem.

Para linguistas aplicados, a perspectiva histórico-cultural traz importantes implicações a respeito de como estudar crenças. Compreender as histórias de sucesso e fracasso na aprendizagem de inglês no contexto nacional, por exemplo, requer não apenas a perspectiva do sujeito, mas sua relação dinâmica com o contexto e a interpretação que ele constrói dessa relação complexa (os interesses pessoais para querer aprender, suas intenções, dentre outros fatores).

Consideramos a relevância de estudar crenças no ensino de línguas pela dinamicidade e complexidade também da experiência humana. Nosso interesse não é apenas de falar sobre o sotaque, pois sabemos que ele existe e faz parte de nossa identidade (BARCELOS, 2003). O que queremos é compreender como os alunos interpretam o próprio sotaque, quais os padrões que eles

sociedade unificada coletivamente. Amparado no materialismo histórico-dialético, esse grupo estudou, na relação entre o cultural e o biológico, o desenvolvimento das funções psicológicas superiores (atenção, memória, percepção). $O$ olhar dialético para uma Psicologia que analisava o desenvolvimento humano a partir de práticas específicas como a educação (relações entre ensinar e aprender) é que torna a teoria histórico-cultural tão relevante nos dias atuais. As implicações sobre pensar o processo educativo como propulsor do desenvolvimento humano ressalta o valor e o potencial dos professores e alunos, fomentando discussões contemporâneas em diferentes áreas, como no caso deste artigo. 
estabeleceram para si como os que devem ser seguidos, e quais as implicações de suas crenças para a própria aprendizagem, sejam elas advindas tanto das experiências de aprendizagem (influência dos professores) ou pela vida numa sociedade brasileira (contextos onde ecoam discursos diversos) que almeja fortalecer seu impacto internacional. Antes disso, é importante considerar também o que se entende por sotaque.

De acordo com Richards e Schmidt (2002), o conceito de sotaque nos manuais de Linguística Aplicada abarca três questões centrais, delineadas no quadro abaixo.

Quadro 1 - O conceito de sotaque na LA

\begin{tabular}{|c|c|c|}
\hline \multicolumn{3}{|c|}{ SOTAQUE (ACCENT) } \\
\hline \multicolumn{3}{|c|}{$\begin{array}{l}\text { Uma forma particular de falar que diz ao ouvinte algo sobre o contexto do falante. A } \\
\text { pronúncia de uma pessoa pode mostrar: }\end{array}$} \\
\hline $\begin{array}{l}\text { a) A região ou país de } \\
\text { onde eles vêm,ex: } \\
\text { - um sotaque do norte } \\
\text { - um sotaque norte- } \\
\text { americano }\end{array}$ & $\begin{array}{l}\text { b) Qual classe social } \\
\text { eles pertencem, ex: } \\
\text { - um sotaque de classe } \\
\text { média baixa }\end{array}$ & $\begin{array}{l}\text { c) Se o falante é ou } \\
\text { não um falante } \\
\text { nativo da língua, ex: } \\
\text { - Ela fala inglês com um } \\
\text { sotaque/ com um sotaque } \\
\text { alemão }\end{array}$ \\
\hline
\end{tabular}

Fonte: Richards e Schmidt (2002, p. 3), verbete adaptado para este quadro.

A definição dicionarizada apresentada anteriormente considera sotaque enquanto forma particular de falar que revela traços do contexto do sujeito, ao passo que constitui sua individualidade e marca seu pertencimento a um determinado grupo social. Isto se relaciona ao fato de que "o sotaque, como a linguagem, está intimamente relacionado à identidade de alguém" (BARCELOS, 2003 , p.14). No desdobramento do conceito são apresentados ainda três fatores evidenciados pelo sotaque de alguém: sua designação geográfica, socioeconômica e linguística.

Considerando a singularidade do falante que se evidencia em seu sotaque, o esperado seria que seu jeito de falar não fosse motivo de grande preocupação do aluno que aprende uma nova língua, afinal seu sotaque faz parte de sua 
individualidade, que por sua vez está inserida em um contexto social ${ }^{7}$. O que se vê no ensino de línguas, no entanto, é o cenário oposto que já adiantamos: permanece a idealização do sotaque do falante nativo (SFN). A este respeito, Graddol (2006, p.217) explica que "uma das ideias mais anacrônicas sobre o ensino de inglês é que os aprendizes deveriam adotar um sotaque do falante nativo". É obsoleto reforçar essa crença que tenta homogeneizar o sotaque do aprendiz para soar como nativo quando consideramos que atualmente o número de falantes de inglês como língua estrangeira (LE) ou língua franca no mundo é bem maior que a quantidade de falantes nativos (CANAGARAJAH; WURR, 2011; GRADDOL, 2006; HALL, 2011; KUMARAVADIVELU, 2012). Dessa forma, o mundo fala com diferentes sotaques e todos são eles igualmente válidos, principalmente quando temos como objetivo comum a interação, a comunicação e a criação de sentido.

O caminho pedagógico a partir disso é promover oportunidades em sala de aula para que os alunos ampliem seus conhecimentos, mesmo aqueles baseados em crenças aparentemente bem sólidas. Do ponto de vista instrucional, as crenças dos alunos podem ser utilizadas como ponto de partida, pois com o seu mapeamento, o professor consegue estabelecer onde a turma quer (e pode) chegar, aliando tantos as formas de aprender que os alunos acreditam serem as mais efetivas, bem como introduzindo outras possibilidades não familiarizadas.

Na Linguística Aplicada brasileira, existem alguns trabalhos que abordaram a temática das crenças sobre o sotaque de falantes nativos na perspectiva de falantes estrangeiros ${ }^{8}$. O estudo de Barcelos (1995), por exemplo, apontou as crenças de alunos de Letras em formação inicial que idealizam o exterior como o ambiente propício para aprender, aperfeiçoar ou "pegar" o sotaque,

\footnotetext{
${ }^{7} T a l$ relação no desenvolvimento humano é descrita, em Psicologia, por Vygotsky e Luria (1993) como a relação entre as linhas biológicas e culturais da espécie, e por Vygotsky (1978) pelas relações interpessoais internalizadas no nível intrapessoal.

${ }^{8}$ Considere os mapeamentos de pesquisas de crenças das últimas décadas como Barcelos (2007) que apontam temas centrais como a formação de professores (relação crenças e prática pedagógica), a possibilidade de aprender em contextos como a escola pública, dentre outros temas mais recorrentes.
} 
corroborando o que foi dito anteriormente a respeito do falante nativo (FN) como referência do falar corretamente.

Em outra investigação, Barcelos (2003) analisou textos jornalísticos, por meio de um banco de dados na internet, evidenciando algumas crenças que ecoam nestes textos e revelam atitudes do brasileiro em relação ao sotaque. 0 trabalho tece algumas considerações interessantes pautadas nos estudos de identidade, apontando que assim como a língua, o sotaque também é fator constituinte da individualidade do falante/aprendiz.

Cruz (2007) fez um levantamento das crenças de alunos de Letras sobre a própria pronúncia no nordeste brasileiro. As oito alunas de um curso de Letras (inglês) de uma instituição federal revelaram que identificam e reconhecem ter um sotaque brasileiro e "inteligível", mas ao mesmo tempo valorizam o SFN como referência, como algo desejado por parte do estudante de LE.

Santos (2010) também contemplou brevemente a questão do sotaque ao analisar as crenças de alunos de Letras sobre o papel da pronúncia na formação, especialmente na questão dos padrões que os alunos tomam como norteadores de sua aprendizagem. A autora sugere, por exemplo, que no estudo de crenças "é importante desmistificar ideias errôneas que muitos graduandos, futuros professores da LI, ainda sustentam" (SANTOS, 2010, p.4). Ainda que as crenças possam impactar as ações dos alunos dificultando suas experiências de aprendizagem, é preciso cuidado com a ideia de tratá-las como errôneas. As crenças fazem parte da compreensão individual do sujeito e assim, abordá-las dessa forma pode intimidar o aluno, que construiu determinado sentido ao longo de anos de experiência. Uma possível alternativa é abrir o espaço para que o próprio sujeito tome consciência do impacto de suas crenças e se o caminho possível for o da mudança, que ele possa contar com seu professor.

De maneira geral, o que se pode observar além da forte presença do sotaque do FN como referência é que os estudos de crenças disponíveis na LA consideram principalmente os alunos dos cursos de Letras. Constatada essa lacuna, propomos neste artigo a análise de crenças de um grupo diferente, mas 
que também necessita da LI para seu trabalho. Antes de apresentarmos nossa análise, gostaríamos de discutir ainda sobre a questão do falante nativo e sua visão sobre sotaques de falantes estrangeiros de inglês.

\section{O papel do sotaque no mundo globalizado}

A relação entre aprendizagem de línguas e o sotaque dos falantes tem interessado, nas últimas décadas, não apenas linguistas aplicados, mas outros pesquisadores das Ciências Humanas. No campo da Psicologia Social, houve nos últimos anos o interesse de compreender como falantes nativos de inglês reagem aos sotaques estrangeiros falando o mesmo idioma. Lev-Ari e Keysar (2010), por exemplo, conduziram dois experimentos com falantes nativos norte-americanos acerca da dificuldade de compreender sotaques não nativos e a relação entre 0 que dito e o que é crível.

O primeiro experimento foi realizado com trinta (30) falantes nativos de inglês. Os pesquisadores solicitaram previamente que três falantes nativos, três não nativos com um sotaque considerado suave (moderado) e três com sotaque acentuado (marcado) gravassem 45 frases em inglês sobre conhecimentos gerais, do tipo: "Uma girafa consegue ficar sem água por mais tempo que um camelo9". Posteriormente, cada uma das trinta pessoas ouviu uma média de 15 frases lidas por cada tipo de sotaque (nativo, suave e acentuado).

As pessoas estavam cientes que as informações lidas foram oferecidas pelos pesquisadores, ou seja, independentemente de quem leu e do seu conhecimento pessoal. Esse procedimento também excluía qualquer informação adicional sobre a origem ou nacionalidade daqueles que gravaram as frases. Os 30 falantes nativos ouviam as frases e indicavam a veracidade em uma linha reta que ia da escala de definitivamente falso até definitivamente verdadeiro. Eles também informavam ao longo do experimento se não conseguiam compreender o que ouviam.

\footnotetext{
${ }^{9}$ No original: "a giraffe can go without water longer than a camel can". (LEV-ARI; KEYSAR, 2010, p.1094).
} 
Os resultados sugerem que "mesmo quando os falantes apenas transmitem informação de outros, as pessoas percebem essa informação como menos verdadeira quando o falante tem um sotaque" (LEV-ARI; KEYSAR, 2010, p.1095). Dito de outra forma, mesmo sem saber especificamente o sotaque por trás daquelas produções sonoras, o que foi dito pelos falantes estrangeiros foi interpretado pelos falantes nativos como "não verdadeiro".

O segundo experimento avaliou se os julgamentos de verdade sofreriam influência da dificuldade de compreender o que foi dito. Os pesquisadores informaram aos participantes que a pesquisa avaliaria "se a dificuldade de compreender a fala influencia julgamentos de verdade, e pediram que eles classificassem a dificuldade de compreensão de cada falante" (LEV-ARI; KEYSAR, 2010, p.1095). Nesta etapa, os pesquisadores contaram com vinte e sete (27) falantes nativos de língua inglesa. Depois de avaliarem a veracidade das frases ouvidas (semelhante ao experimento anterior), eles classificaram o nível de compreensão das frases em uma escala cujas extremidades iam de muito fácil até muito difícil. Lev-Ari e Keysar (2010, p.1095) observam que, se por um lado os participantes consideraram as informações lidas por falantes nativos e outros com sotaque moderado como verdadeiras, por outro, "eles classificaram enunciados fortemente acentuados como menos verdadeiros que os outros." (grifos nossos).

Em ambos os experimentos, uma das limitações é que a relação entre sotaque e estereótipo ou preconceito não foi abordada pelos pesquisadores, uma vez que os sujeitos não sabiam a origem das pessoas que leram as frases com conhecimentos triviais. Todavia, os autores ao concluírem, reconhecem que em nossa sociedade "os falantes são frequentemente mais do que mensageiros, e os estereótipos estão propensos a desempenhar um papel posterior" (LEV-ARI; KEYSAR, 2010, p.1095). Dessa forma, mesmo que o sotaque não tenha sido nomeado ao longo do experimento, ele é percebido pelos falantes nativos e como apontaram os resultados, sua presença influencia o julgamento se o que é dito é verdadeiro ou não, conforme o grau de intensidade desse sotaque. Faz-se 
necessário, dessa forma, mais estudos que incorporem essa questão de estereótipos e como eles também se relacionam ao conjunto de crenças que as pessoas têm sobre diferentes sotaques.

Esses resultados possibilitam inferir que as crenças dos aprendizes de inglês como LE, conforme discutimos na seção anterior, não se originam aleatoriamente ou sem uma relação com a cultura e a vida social. Elas refletem ideias, experiências, percepções e discursos que atravessam as interações cotidianas das pessoas. Se os falantes nativos tendem a confiar mais nos sotaques menos marcados, podemos compreender porque a crença do falante estrangeiro em querer soar como nativo permanece ainda tão evidente.

Com este cenário, podemos introduzir os participantes que serão foco deste estudo. Tivemos acesso a um grupo de alunos de nível superior cuja aprendizagem de línguas é bastante presente não só nos trabalhos acadêmicos, mas também na grade curricular. Um perfil desses alunos é apresentado a seguir, bem como o detalhamento da coleta e análise dos dados.

\section{Estudando as crenças}

Considerando a ausência de estudos de crenças com foco em outros cursos universitários, não necessariamente voltados para a formação de professores de línguas, mas que também possibilitam a aprendizagem de uma nova língua, este trabalho busca mapear um perfil inicial das crenças de uma turma de universitários em uma disciplina de inglês.

Dessa forma, elaboramos um questionário semi-estruturado com questões abertas e fechadas. As questões fechadas tinham por objetivo traçar um perfil da turma sobre a) anos de escolaridade em instituições públicas, privadas e cursos livres de idiomas, b) os fatores de maior e menor relevância na aprendizagem destes alunos no ensino superior e c) a importância que os alunos atribuem ao fato de querer ter um sotaque próximo ao do falante nativo. Nas questões abertas, os alunos puderam expor sua opinião sobre o papel das atividades de 
pronúncia na aula de inglês e o sotaque na aprendizagem e no uso da língua inglesa.

Em linhas gerais este estudo se orientou pelos seguintes questionamentos:

(I) Quais as crenças destes alunos sobre o sotaque do falante nativo?

(II) Qual a importância que atribuem aos exercícios de pronúncia em relação aos outros tipos de atividade que desenvolvem na disciplina de língua inglesa (LI)?

(III) Estes alunos estão preocupados em ter um sotaque próximo do falante nativo (SFN)? E qual a justificativa para esta crença?

Neste artigo, propomos algumas reflexões para tentar responder estes três questionamentos. No próximo item, traçamos um perfil do grupo de universitários.

\section{Contexto e participantes}

Participaram deste estudo 21 alunos do primeiro ano de um curso de Secretariado Executivo Trilíngue ${ }^{10}$. Os estudantes cursavam a segunda disciplina de língua inglesa no segundo semestre letivo de uma universidade federal mineira. Três estudantes (3) estudaram pelo menos onze anos em escolas públicas. Sete frequentaram escolas particulares (7) pelo menos onze anos e os onze demais (11) estudaram nos dois tipos de escola, com maior tempo de estudo em escolas públicas. Os alunos são oriundos de diversos estados do Brasil sendo, assim, uma turma bastante heterogênea. A respeito dos cursos e idiomas, quatro $\left(04^{11}\right)$ estudantes nunca estudaram em cursos livres, ao passo que a grande maioria (17) tem no mínimo entre um ano e meio ou dois de estudos. Há

\footnotetext{
${ }^{10}$ As línguas estrangeiras estudadas por estes alunos são: Inglês, Espanhol e Francês.

${ }^{11}$ Dois desses quatro alunos justificam terem aprendido LI por conta própria, lendo livros, assistindo filmes e ouvindo música (além das aulas na escola regular). Os dois demais justificam que o conhecimento que possuem vem da escola regular e dos bons professores que afirmam terem tido.
} 
dois casos específicos na turma que merecem ser mencionados. Um dos alunos fez seu curso de inglês nos Estados Unidos onde morou por um ano. Há também pelo menos oito (08) alunos com mais de cinco anos de estudo em escolas de línguas. Dessa forma, é possível observar que a turma possui um bom nível de proficiência já no primeiro ano do curso.

Em uma turma com bom nível linguístico, buscamos observar algumas crenças sobre a pronúncia e a respeito do sotaque do falante nativo de inglês. Na próxima seção, apresentaremos um panorama dessas crenças mapeadas e que serão ilustradas com perspectivas dos alunos.

\section{Análise de dados}

Os dados foram analisados qualitativamente seguindo parâmetros da análise de conteúdo (PATTON, 1990; DÖRNYEI, 2007; SALDAÑA, 2009). Este tipo de análise consiste na observância de padrões e tópicos que emergem dos dados e que auxiliam na codificação e categorização de temas. Os gráficos foram elaborados com base nas questões fechadas, e as respostas das questões abertas foram analisadas e categorizadas qualitativamente conforme apresentamos na seção a seguir. Cada aluno mencionado na próxima seção será representado por um nome fictício, por questões éticas.

\section{Aulas de inglês: 0 que queremos e o que esperamos?}

A partir dos dados coletados, foi possível traçar um perfil dos interesses daqueles alunos sobre a própria aprendizagem. Inicialmente, buscamos verificar qual a importância que estes alunos atribuíam à pronúncia e aos exercícios voltados para esta habilidade. 
"Ter ou não ter? eis a questão!" Crenças de alunos de secretariado executivo sobre o sotaque do falante nativo de inglês

Fonte: $\mathrm{O}$ autor.

Figura 1 - A pronúncia na aula de inglês ${ }^{12}$

\section{Qual a importância da pronúncia na aula de inglês?}

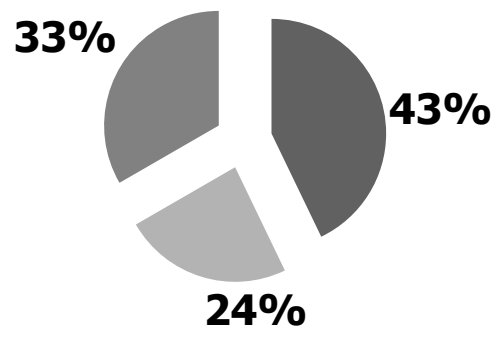

- Muito importante

Importante

não é muito importante

A maioria dos alunos (43\%) considera a pronúncia muito importante dentre as atividades a serem desenvolvidas na sala de aula. A disciplina de LI na universidade é vista como espaço propício para solucionar os últimos "problemas" que os alunos possuem de suas experiências anteriores, antes de enfrentarem o mercado de trabalho, conforme ilustrado na explicação de uma das alunas.

\footnotetext{
"[A Pronúncia] é muito importante, pois [a disciplina de inglês] é como a última chance para desenvolvê-la quanto mais a gente puder, antes de alcançar o mercado de trabalho. É a última chance dos alunos serem alunos, podendo cometer erros que não serão prejudiciais para eles. É o que eu tento fazer, melhorar minha pronúncia o máximo que posso."(Amanda)
}

Observamos neste excerto que Amanda vê na disciplina a oportunidade de tirar as últimas dúvidas e de eliminar as últimas falhas para assim poder atuar no mercado de trabalho. Nota-se também certa preocupação com a própria pronúncia, que é justificada pelo fato de que ali ela tem tentado desenvolver e trabalhar essa questão. Há também alunos que consideram a pronúncia como importante $(24 \%)$, mas possuem outras prioridades ao cursar essa disciplina, conforme ilustrado no excerto a seguir.

\section{Excerto 2}

${ }^{12}$ As perguntas utilizadas nos gráficos são as mesmas respondidas pelos alunos no questionário. 
"Ter ou não ter? eis a questão!" Crenças de alunos de secretariado executivo sobre o sotaque do falante nativo de inglês

[A Pronúncia] é necessária para uma boa compreensão. Eu faço essa disciplina para praticar meu inglês e aumentar meu vocabulário. Eu não pretendo falar como um nativo, apenas quero ser compreendida. Quero falar o melhor que puder. (Luana)

Neste excerto, Luana ressalta que sua prioridade pessoal na disciplina é ampliar vocabulário nas atividades orais. Revela ainda não se preocupar em querer ter um sotaque próximo do falante nativo, mas é cuidadosa ao afirmar que o importante é ser compreendida na comunicação. Do total, $24 \%$ consideram a pronúncia um fator importante, mas assim como Luana, revelam ter outras prioridades na disciplina.

Quanto aos demais (33\%), uma considerável parcela considera a pronúncia como um aspecto não muito importante. Observe a explicação da participante Adriana que ilustra as respostas deste grupo.

\section{Excerto 3}

"Eu acho que a pronúncia é importante, mas não é mais importante que o listening ou a gramática, por exemplo, porque se você não tem uma boa pronúncia, mas tem uma boa gramática, as pessoas te entenderão mesmo quando você falar "errado".(Adriana)

A compreensão auditiva e a própria gramática são apontadas nesta justificativa como mais importantes, inclusive nas situações reais de comunicação, pois Adriana sugere que o bom conhecimento gramatical pode ser mais importante para uma boa compreensão do que necessariamente um "falar errado", que aqui interpretamos como uma pronúncia diferente do inglês padrão ${ }^{13}$ do nativo, ou seja, com sotaque.

Além de compreender o que eles pensam sobre a pronúncia, buscamos mapear como eles vêem este aspecto linguístico junto aos demais tipos de atividades. A figura a seguir mostra que, em geral, a pronúncia fica em posição mais inferior.

\footnotetext{
${ }^{13}$ Inglês padrão (Standard English) ou variedade padrão (Standard Variety) é aqui compreendido como "a variedade de uma lingual que tem o maior status em uma comunidade ou país e que está geralmente baseada na fala e na escrita de falantes nativos escolarizados de uma língua." (RICHARDS; SCHMIDT, 2002, p.509).
} 
Figura 2 - Aspectos mais importantes na aula de inglês

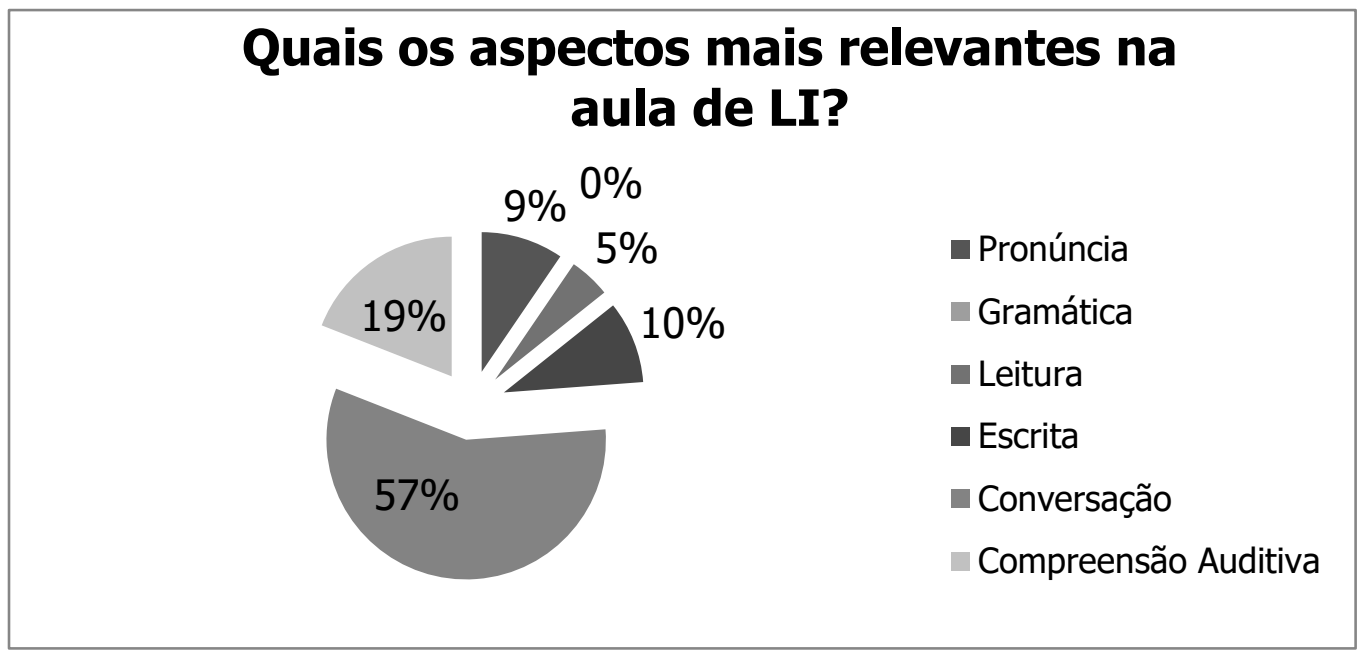

Fonte: $\mathrm{O}$ autor.

A pronúncia figura como o quarto aspecto mais relevante para ser trabalhado $(9 \%)$. Nenhum dos alunos $(0 \%)$ selecionou a gramática como tópico para estudo mais aprofundado. A leitura é uma habilidade menos relevante em relação à pronúncia, assinalada por um pequeno grupo (5\%), possivelmente por fazerem isso por conta própria fora da sala de aula, tendo outras prioridades para os encontros presenciais. A escrita é selecionada como mais relevante por $10 \%$ dos alunos, que justificam a necessidade do secretário executivo possuir, além da proficiência oral a competência necessária para redigir documentos em língua estrangeira, bem como outros gêneros que estão aprendendo no ensino superior.

O excerto abaixo mostra o exemplo de um dos alunos do grupo que não considera a pronúncia como o aspecto mais relevante da disciplina:

\section{Excerto 4}

"Acho que a pronúncia é importante para a pessoa que precisa se comunicar com os outros. Mas neste momento, pra falar a verdade, minha necessidade é a leitura e listening. "(Luhan)

Ainda que ele reconheça o papel da pronúncia para a comunicação, ele aponta que atualmente seus interesses atuais são o desenvolvimento da leitura e da compreensão auditiva. Os alunos, em geral, não descartam que aprender a 
produção sonora tem papel importante, mais deixam ela mais abaixo da lista de prioridades. É o que mostra também o próximo excerto.

Excerto 5

"[Pronúncia] é muito importante, mas agora eu quero aprender gramática, a escrita, o listening e a conversação primeiro, e então melhorar minha pronúncia. (Mayara)

O excerto de Mayara é semelhante ao de Luhan ao não desvalorizar a posição da pronúncia, no entanto, ela estabelece uma hierarquia de prioridades, sendo a pronúncia o último aspecto a ser trabalhado após desenvolver suas capacidades de interagir na língua alvo ${ }^{14}$.

O que podemos concluir nesta primeira seção é que se olhada isoladamente, os alunos consideram a pronúncia deles como algo muito importante, no entanto, se olhada no conjunto de atividades desenvolvidas na disciplina, outras habilidades dominam a preferência do grupo, especialmente a oralidade. Neste momento, é mais desejável saber falar antes de preocupar-se em como produzir os sons da fala.Tendo essa primeira constatação, abordaremos a seguir a questão do sotaque do falante nativo (SFN).

\section{0 sotaque do falante nativo: é o que queremos?}

Nesta seção, analisamos algumas crenças dos alunos de secretariado executivo sobre o SFN em relação à própria aprendizagem. O perfil mapeado pode ser visualizado na figura a seguir.

\footnotetext{
${ }^{14}$ Vale ressaltar que o uso dos termos speaking e listening figura nas próprias respostas dos alunos ora em inglês, ora em português. Além disso, muitos mencionam em suas respostas 0 termo "conversação" para se referir à oralidade. Para facilitar a aplicação do questionário, por exemplo, optamos por esse termo apesar de considerarmos mais amplamente a questão das capacidades orais.
} 
Figura 3 - Sobre o sotaque do falante nativo

\section{Você se preocupa em ter sotaque semelhante ao do falante nativo?}

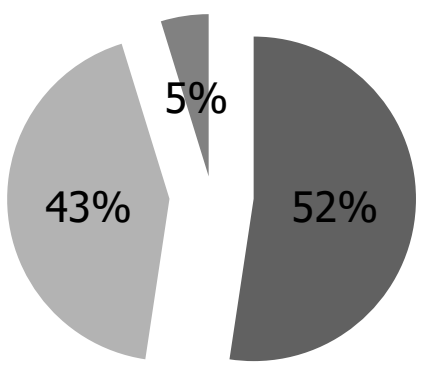

$\square \operatorname{Sim}$

não

- Nunca pensei sobre o assunto

Fonte: $\mathrm{O}$ autor.

Mais da metade dos alunos (52\%) revela se preocupar de fato com o sotaque do falante nativo, buscando, portanto, desenvolver ao longo dos anos de aprendizagem uma pronúncia que pudesse estar cada vez mais próxima daquela desejada. Os demais (43\%) não revelam tal preocupação, ao passo que uma parcela menor (5\%) nunca parou para pensar sobre o assunto. Dentre as justificativas que ressaltam o desejo e a busca pelo SFN, salientamos algumas que evidenciam crenças específicas dos alunos e como eles as justificam.

\section{Excerto 6}

"Porque eu pretendo ir para os Estados Unidos para melhorar meu inglês, e como já ouvi falar, os americanos não são amigáveis com os estrangeiros, especialmente quando eles não os entendem muito bem. Então, eu tento falar o mais próximo que eu consigo da pronúncia americana, assistindo séries, ouvindo bandas americanas que eu gosto. "(Amanda)

Amanda justifica neste excerto sua crença na importância de ter um sotaque próximo ao dos nativos pelo possível medo da rejeição deles, pois acha que eles não são receptivos aos sotaques mais difíceis de compreender. Ela revela ainda que futuramente pretende viajar para o país cujo sotaque toma como referência. Por ter aprendido LI no Brasil, ela acredita que indo para o exterior poderá acertar os últimos detalhes e especialmente aprimorar sua 
pronúncia. Grande parte das justificativas corrobora a visão de Amanda, pois os demais alunos enfatizam que uma boa pronúncia (aquela que se aproxima do SFN) é fator necessário para a futura carreira. 0 excerto a seguir oferece outro exemplo.

\section{Excerto 7}

" Porque quero soar o mais próximo possível da pronúncia correta, assim eu gostarei mais do Inglês, e é bom para minha carreira também." (Carolina)

Aqui é possível observar uma crença que concebe o SFN como sendo um parâmetro para a pronúncia correta, nesta perspectiva, os demais falantes nãonativos provavelmente são desviantes do sotaque idealizado. Almejar este tipo de pronúncia está relacionado com questões de gosto pessoal e afetividade, pois a aluna afirma que gostará ainda mais da língua inglesa, criando assim algumas expectativas futuras bastante positivas. Além disso, a associação entre a maneira como os alunos de secretariado falam inglês e as oportunidades que poderão ter na carreira revelam como as noções idealizadas de mundo globalizado e inglês como exigência do mercado de trabalho permeiam os discursos dos alunos, algo que já sinalizado por outros linguistas aplicados (PENNYCOOK, 1994; SCHMITZ, 2012, 2016). Observe ainda o que outra estudante diz:

\section{Excerto 8}

"É melhor ter uma pronúncia próxima de um falante nativo, porque na minha futura carreira profissional eu estarei em contato com estrangeiros. Além disso, eu espero poder trabalhar com traduções e sei que quando fizer a minha entrevista de emprego, eles confiarão em mim se eu tiver uma boa pronúncia. (Nina)

Este excerto apresenta mais uma justificativa pautada nos benefícios do sotaque próximo ao do falante nativo na carreira profissional. Podemos observar o quanto Nina projeta suas expectativas futuras ao explicar sua crença. Com o desejo de trabalhar com estrangeiros, ela acredita que assimilar um sotaque nativo (e consequentemente apagar os traços de seu sotaque de falante estrangeira) vai assegurar sucesso profissional em sua área. 0 que sua resposta não revela, no entanto, são as origens dessa projeção que ela faz entre o FN 
como indicativo de sucesso e quais as implicações disso para sua própria aprendizagem. No geral, esses excertos remetem ao estudo de Lev-Ari e Keysar (2010), quando os participantes salientam que uma boa pronúncia está relacionada à confiabilidade por parte do falante nativo. Sua crença reflete 0 papel hegemônico do inglês e a ideia de a aprendizagem do idioma é uma garantia direta de melhores oportunidades (PENNYCOOK, 1994).

Os demais alunos (43\%) justificam terem outras prioridades na aprendizagem de línguas, tendo até opiniões bastante esclarecidas a respeito de ter ou não um sotaque como o de um nativo ou ter um sotaque brasileiro (BARCELOS, 2003). É o que pode ser observado na justificativa de uma das alunas.

\section{Excerto 9}

"Falar como um nativo não é o meu objetivo. Como brasileira, eu não tenho um sotaque forte, porque eu venho de um estado sem um sotaque "diferente". O que eu quero dizer é que tenho estudado bastante, e por muito tempo, para falar e escrever corretamente, eu sou brasileira e isso nunca vai mudar". (Jacqueline)

Jacqueline demonstra que não se preocupa com questões de sotaque nativo ou estrangeiro por este não ser seu objetivo. Além disso, tenta fortalecer esta perspectiva sugerindo que por ter vindo de um estado onde acredita que as pessoas não têm um sotaque marcado, nunca teve problemas com isso (revelando aqui outra crença dela). Mesmo com anos de estudo em que tem buscado se aprimorar ainda mais na competência linguística, não se esquece de sua identidade nacional, a qual segundo ela não vai mudar. Crenças deste tipo reforçam uma visão mais tolerante dos alunos, que aprendem uma língua estrangeira pelas necessidades do mundo globalizado (CANAGARAJAH, 2011; GRADDOL, 1997, 2006; HALL, 2011; KUMARAVADIVELU, 2012; SCHMITZ, 2012, 2016). Uma visão de aluno que possivelmente concebe esta língua mais como global, utilizada por falantes de diversas nacionalidades e não somente para interagir com falantes nativos, e, portanto, não acredita na necessidade ou exigência de que todos falem da mesma forma, com um mesmo sotaque. Ainda assim, tal reflexão parece não ter sido realizada pelos alunos daquele grupo e a 
maioria (52\%) ainda toma o falante nativo como parâmetro de referência. Mesmo que o sotaque revele traços pessoais do aprendiz (RICHARDS; SCHMIDT, 2002), os alunos de secretariado parecem subestimar a singularidade de estrangeiro para soar como um nativo, com expectativas de que isso trará melhores oportunidades ou aceitação.

\section{Comentários finais}

Este artigo discutiu as crenças de alunos de um curso de secretariado executivo sobre o sotaque em um contexto de disciplina universitária de língua inglesa. O mapeamento das crenças partiu do papel da pronúncia na aula de inglês, dos interesses dos alunos na disciplina para então abordar como eles concebem o sotaque do falante nativo na própria aprendizagem. Como discutido em trabalhos anteriores (BARCELOS, 1995, 2003; CRUZ, 2007; SANTOS, 2010) os resultados que apresentamos corroboram a perspectiva de que estes estudantes brasileiros também valorizam o SFN como norma ou padrão a ponto de afirmarem, por exemplo, ser esta a forma correta ou ideal de falar.

Como apontado por outros trabalhos (LEV-ARI; KEYSAR, 2010), essas crenças têm relação com a vida em sociedade. Ou seja, elas não são aleatoriamente projetadas, pois de alguma forma refletem e revelam o sentido das outras pessoas, neste caso o de que os falantes nativos preferem sotaques menos marcados. A partir do que discutimos anteriormente, três questões podem ser levantadas:

Considerada isoladamente, a pronúncia é entendida como um fator muito importante nas atividades desenvolvidas em sala de aula. A figura 1 mostrou que quase a metade dos alunos (43\%) considera a disciplina de língua inglesa como a última oportunidade de reparar as falhas remanescentes na pronúncia, para adquirir mais vocabulário e principalmente participar das atividades com foco na oralidade.

Considerada junto com os demais fatores da aula, a pronúncia fica em segundo plano, sendo uma preferência esclarecida pelo trio: conversação, escrita 
e compreensão auditiva. Os dados apontam que escrever, ouvir e comunicar-se são as grandes prioridades dos alunos e que a pronúncia figura em quarto lugar, com $9 \%$ (retome os dados apresentados na figura 2). Mesmo aqueles universitários com bom nível de proficiência, eles vêem a disciplina como forma de aperfeiçoar a competência linguística que já possuem. Antes de ficarem preocupados com a maneira de falar inglês, os alunos revelaram que se preocupam em falar inglês com segurança.

O sotaque do falante nativo ainda é a referência a ser alcançada pelo aluno estrangeiro. Entre os participantes, constatamos que mais da metade (52\% conforme apontado na figura 3) tomam o SFN como referência. Dessa forma, ele não é visto apenas enquanto parâmetro de como falar corretamente, mas é também equiparado ao sucesso profissional. Há uma aparente idealização de que o bom profissional não é apenas aquele capaz de se comunicar, mas aquele que parece um nativo. Ao mesmo tempo, os alunos parecem não refletir que essa crença implica no apagamento de traços de sua subjetividade, de seu contexto cultural.

Essas implicações mostram a necessidade de promover oportunidades para que os alunos tomem consciência de determinadas especificidades da aprendizagem, como no caso do sotaque. É importante que os alunos considerem as implicações de almejar um sotaque externo em detrimento ao seu modo particular, brasileiro, de falar inglês. Problematizar as crenças na sala de aula pode ser o começo dessa conscientização. Os alunos podem orientar seus esforços para aperfeiçoar a maneira como produzem os sons da língua alvo, mas podem fazê-lo por vontade própria, tendo convicção de que um sotaque estrangeiro não é uma limitação a ser superada. Por fim, levando a uma compreensão da língua inglesa mais coerente ao mundo contemporâneo (CANAGARAJAH; WURR, 2011; HALL, 2011; KUMARAVADIVELU, 2012; SCHMITZ, 2016), onde o número de falantes de inglês como língua internacional é superior ao de falantes nativos. O mundo atualmente fala inglês com diferentes sotaques e precisamos reconhecer fatores mais importantes ao processo como a 
construção de significados e, como sugere Jenkins (2007) o direito de expressar as ideias em uma nova língua com liberdade.

A partir disso, concluímos ser importante investigar mais a fundo estas relações que alguns alunos fizeram entre o sotaque e sucesso profissional, observando se tais práticas têm gerado problemas para a aprendizagem do aluno. Seria importante averiguar também se as empresas que contratam esses profissionais corroboram essa visão dos alunos e se não seria essa mais uma projeção feita por esses futuros secretários. Acreditamos que a aula de línguas é propícia para esse debate, para discutir sobre as crenças enquanto se aprende essa nova língua, para que os próprios alunos sejam capazes de observar e refletir quais implicações suas crenças tiveram e têm em suas experiências de aprendizagem. E que dessa forma, a formação profissional deles englobe uma perspectiva contemporânea mais ampla de como o inglês pode ser falado em diferentes partes do mundo e com diferentes sotaques.

\section{Referências}

BARCELOS, A.M.F. A cultura de aprender língua estrangeira (inglês) de alunos de Letras. 1995. Dissertação (Mestrado em Lingüística Aplicada) - Universidade Estadual de Campinas, Campinas, 1995.

. What is wrong with a Brazilian accent? Horizontes de Linguística Aplicada, Brasília, v. 2, n.1, p. 7-21, 2003.

. Crenças sobre ensino e aprendizagem de línguas: reflexões de uma década de pesquisa no Brasil. In: ALVAREZ, M. L. O.; SILVA, K. A. (Org.). Linguistica Aplicada: Múltiplos Olhares. Campinas: Pontes, 2007. p. 27-69.

CANAGARAJAH, A.S.; WURR, A.J. Multilingual Communication and Language Acquisition: New Research Directions. The Reading Matrix, v.11, n.1, p.1-15, 2011.

CRUZ, N. C. Crenças de graduandos de Inglês Língua Estrangeira sobre a própria pronúncia. In: CONGRESSO LATINO-AMERICANO SOBRE FORMAÇÃO DE PROFESSORES DE LÍNGUAS, 2., 2007, Florianópolis. p. 360-373. 
DÖRNYEI, Z. Research Methods in Applied Linguistics: quantitative, qualitative and mixed methodologies. Oxford: Oxford University Press, 2007. 336p.

GRADDOL, D. The Future of English? A Guide to forecast the popularity of the English Language in the 21st century. London: British Council, 1997. 65p.

. English Next. London: British Council, 2006. 128p.

HALL, G. Exploring English Language Teaching: Language in Action. New York: Routledge, 2011. 282p.

HARMER, J. The practice of English Language Teaching. $3^{\text {rd }}$. ed. Harlow: Pearson Education, 2001.

JENKINS, J. The Phonology of English as an International Language. Oxford: Oxford University Press, 2000.

. English as a Lingua Franca. Oxford: Oxford University Press, 2007.

KUMARAVADIVELU, B. Language Teacher Education for a Global Society: a modular model for knowing, analyzing, recognizing, doing and seeing. New York: Routledge, 2012. 132p.

LEV-ARI, S.; KEYSAR, B. Why don't we believe non-native speakers? The influence of accent on credibility. Journal of Experimental Social Psychology, New York, v.46, n.6, p.1093-1096, 2010.

PATTON, M.Q. Qualitative evaluation and research methods. $2^{\text {nd }}$ ed. Newbury Park, CA: SAGE, 1990. 598p.

PENNYCOOK, A. The Cultural Politics of English as an International Language. London: Longman, 1994.

RICHARDS, J.C.; SCHMIDT, R. Longman Dictionary of Language Teaching and Applied Linguistics. $3^{\text {rd }}$. ed. London: Pearson Education, 2002. 595p.

SALDAÑA, J. The coding manual for qualitative researchers. London: SAGE, 2009. 223p.

SANTOS, T. J. P. Crenças sobre pronúncia na formação de professores de lingual inglesa. Fronteira digital, v.2, n.2, p. 8-15, 2010.

SCHMITZ, J.R. "To ELF or not to ELF?" (English as a Lingua Franca): That's the question for Applied Linguistics in a globalized world. Revista Brasileira de Linguística Aplicada, Belo Horizonte, v.12, n.2, p.249-284, 2012. 
"Ter ou não ter? eis a questão!" Crenças de alunos de secretariado executivo sobre o sotaque do falante nativo de inglês

. Um mundo globalizado, híbrido, pós-colonizado e pós-

moderno:Reflexões sobre o inglês na atualidade. Folio (Online): Revista de Letras, v. 8, p. 333-365, 2016.

VYGOTSKY, L.S. Mind in Society. Cambridge: Harvard University Press, 1978. $158 \mathrm{p}$.

VYGOTSKY, L.S. Thought and Language. Expanded and revised. Cambridge, MA: MIT Press, 2012. 307p.

VYGOTSKY, L.S.; LURIA, A. Ape, Primitive Man, and Child: Essays in the History of Behaviour. New Jersey: Lawrence Erlbaum Associates, 1993. 